\title{
The online-to-offline (020) food delivery industry and its recent development in China
}

\author{
Xueyin Zhao $\mathbb{1}^{1,2} \cdot$ Wenhui Lin ${ }^{1,2,3} \cdot$ Shuyi Cen ${ }^{1,2} \cdot$ Haoyu Zhu ${ }^{4} \cdot$ Meng Duan ${ }^{1,2} \cdot$ Wei Li ${ }^{1,5} \cdot$ Shankuan Zhu $\oplus^{1,2}$
}

Received: 11 February 2020 / Revised: 18 November 2020 / Accepted: 9 December 2020 / Published online: 2 February 2021

(c) The Author(s), under exclusive licence to Springer Nature Limited 2021

\begin{abstract}
This paper offers a unique perspective about the development of the online-to-offline $(\mathrm{O} 2 \mathrm{O})$ food delivery industry from 2017 to 2019 in China. This study demonstrates the latest transformation and improvements of the $\mathrm{O} 2 \mathrm{O}$ market that address some common problems in the early stages of the development of this raising industry in China. New strategies and regulations from the $\mathrm{O} 2 \mathrm{O}$ platforms, food providers, and national and local governments are discussed. In our view, the mission of the $\mathrm{O} 2 \mathrm{O}$ industry in general has shifted from pursuing enormous quantity to ensuring high quality. China's $\mathrm{O} 2 \mathrm{O}$ food delivery industry warrants further attention and studies as it grows and develops into the future. We suggest future studies to work on its economic, behavioral, and health impacts on population level as it encompasses both great risks and rewards.
\end{abstract}

\section{Background of the 020 food delivery industry}

A previous published paper about the emerging $\mathrm{O} 2 \mathrm{O}$ food delivery industry in China in 2018 revealed the inevitable trend of increased consumption of food delivery service in China, which acts as a third-party platform between customers and restaurants to coordinate orders and delivery online [1]. The study demonstrated that the market scale of $\mathrm{O} 2 \mathrm{O}$

Wei Li

liwei69@zju.edu.cn

$\bowtie$ Shankuan Zhu

zsk@zju.edu.cn

1 Chronic Disease Research Institute, The Children's Hospital, and National Clinical Research Center for Child Health, School of Public Health, School of Medicine, Zhejiang University, Hangzhou, Zhejiang, China

2 Department of Nutrition and Food Hygiene, School of Public Health, Zhejiang University, Hangzhou, Zhejiang, China

3 Department of Social Medicine and Health Service Management, School of Public Health, Zhejiang University, Hangzhou, Zhejiang, China

4 New York University, New York City, NY, USA

5 Hospital Management Office, School of Medicine, Zhejiang University, Hangzhou, Zhejiang, China food industry increased from US $\$ 3.4$ billion in 2011 to US $\$ 32.5$ billion in 2017 , and the customers of such industry increased from 114 million in 2015 to 343 million in 2017 in China. It also discussed that the increase of food availability and accessibility provided by $\mathrm{O} 2 \mathrm{O}$ food delivery system has brought convenient dining experience. During that time (2015-2017), safety issues and health problems such as foodborne diseases were the major concerns, along with the behavioral changes caused by the $\mathrm{O} 2 \mathrm{O}$ food service and its impact on individual's physical and mental health [1].

\section{The changing demands}

Developments in China's O2O food delivery industry, along with the increased use of internet, have led to changes within the Chinese food delivery customer population as well as in their demands. From December 2017 to June 2019, internet users in China grew from 772 million to 854 million [2]. Within this period, $\mathrm{O} 2 \mathrm{O}$ food delivery customers grew steadily by $22.7 \%$, from 343 million to 421 million [3]. It is evident that the $\mathrm{O} 2 \mathrm{O}$ food delivery customer population has been growing steadily [3]. (Fig. 1). Moreover, $\mathrm{O} 2 \mathrm{O}$ customers used food delivery services more frequently in 2019 than they ever had before, with the average number of orders placed by an individual customer growing from 18.8 in 2018 to 25.5 in 2019 [4]. These findings suggest that the growth of the Chinese $\mathrm{O} 2 \mathrm{O}$ 
Fig. 1 2017-2019 O2O food delivery customer population in China. The figure demonstrates the increase in the customer number of $\mathrm{O} 2 \mathrm{O}$ food delivery system between 2017 and 2019. The user scale is the total number of $\mathrm{O} 2 \mathrm{O}$ service users in China for each time point (unit: ten thousand people). The usage rate shows the percentage of user amont in each time point $(100 \%=$ 500 million) in order to show the increase of users across these years. Data retrieved from the 44th Statistical report on the development of China Internet network by China Internet Network Information Center (CNNIC) in 2019. Available from: http://www.cac.gov.cn/ 2019-08/30/c_1124938750.htm.

\section{Unit: Ten thousand people}



user scale usage rate industry was more driven by the increasing frequency with which customers used its service than by the increase in customer number. This new pattern demonstrates novel developments in $\mathrm{O} 2 \mathrm{O}$ customers' consumption habits.

Customers born in the 80s and 90s dominated the consumption of $\mathrm{O} 2 \mathrm{O}$ food delivery services. A prominent $\mathrm{O} 2 \mathrm{O}$ food delivery platform in China had $86.3 \%$ of its orders placed by customers of between 20 and 34 years old in the first half of 2019 [5]. Surveys reveal that some of the major reasons $\mathrm{O} 2 \mathrm{O}$ customers chose to use food delivery service include "bad weather", "convenience of delivery", and "not wanting to cook" [5]. Customers born in the 90s chose food delivery services primarily because they considered cooking a nuisance, while for customers born before the 90 s weather was the deciding factor [5]. Data show that the percentage of student customers on $\mathrm{O} 2 \mathrm{O}$ decreased from $33 \%$ in 2015 to less than $10 \%$ in 2019 [5]. The percentage of white-collar workers among $\mathrm{O} 2 \mathrm{O}$ costumers have increased from $63 \%$ in 2015 to $86 \%$ in 2019 [6]. This changing makeup of the $\mathrm{O} 2 \mathrm{O}$ customer population may in part explain the increase of higher-priced delivery orders. It is observed that delivery orders above $40 \mathrm{RMB}$ made up $32.9 \%$ of all $\mathrm{O} 2 \mathrm{O}$ delivery orders in the fourth quarter of 2018, as opposed to $22.7 \%$ in the first quarter of 2017 [7]. It is worth pointing out that there might exist a causal connection between a customer's level of education and their $\mathrm{O} 2 \mathrm{O}$ food delivery service consumption level. A recent study concerning Chinese undergrads points out that frequent $\mathrm{O} 2 \mathrm{O}$ food delivery consumption is tied to a relatively high education level [8]. Research has shown that highly educated individuals are more aware of their health than the less-educated ones [9]. We assume that highly educated individuals would be able to accept the increasing price of $\mathrm{O} 2 \mathrm{O}$ service as long as it is able to meet their needs on healthy and high-quality food. This possible explanation is consistent with the rising demand of $\mathrm{O} 2 \mathrm{O}$ service with higher food quality and price.

\section{Shifting goals}

The $\mathrm{O} 2 \mathrm{O}$ food delivery industry's quick rise in China may be accredited to its early business strategies. The majority of $\mathrm{O} 2 \mathrm{O}$ delivery platforms expanded their markets by attracting businesses through generous subsidies and enticing consumers with low, affordable prices during the $\mathrm{O} 2 \mathrm{O}$ food industry's early development period [10]. However, food prices with $\mathrm{O} 2 \mathrm{O}$ service had been on an upward trend since 2018 [11]. According to the Sina Finance report, O2O platform has raised their prices of delivery food, some are even more expensive than the dine-in food produced from the same restaurants [11]. The Sina Finance report also mentioned that all parties in the $\mathrm{O} 2 \mathrm{O}$ food industry have entered a cost recovery period, including labor, rent, social security, disability insurance, and third-party delivery service platform fees. The platform has been inevitably requiring higher intermediate business income [11]. Superficially, this was due to $\mathrm{O} 2 \mathrm{O}$ platforms' higher commission fees on restaurants as well as an increase in delivery fee; both led to increased production costs and resulted in higher product prices [12, 13]. Yet there were deeper reasons: First, as the $\mathrm{O} 2 \mathrm{O}$ delivery industry matured and its early strategies became largely unprofitable, its goal began to shift from market expansion to generating profits; [10] second, delivery services started to focus on producing higher-quality products instead of providing low, affordable prices [14, 15]. 
Table 1 List of goods provided on $\mathrm{O} 2 \mathrm{O}$ food platforms in China.

\begin{tabular}{ll}
\hline Category & Item \\
\hline Delicacy & $\begin{array}{l}\text { Local dish, bento, fast food, snack, hotpot, light food and western food, Japanese } \\
\text { and Korean cuisine etc. }\end{array}$ \\
Snacks and drink & $\begin{array}{l}\text { Snacks, milk tea and juice, bread and cake, coffee, ice cream etc. } \\
\text { Goods from large supermarket, convenience store, water-supply station etc. }\end{array}$ \\
Frocery & Vegetables, fruits, seafood, food material, meat and eggs etc \\
Health and medicine & Drugstore, optical store, etc. \\
Flowers and plants & Flower, green plants.
\end{tabular}

The increased investments in research and development, which resulted in better services and shorter delivery time also resulted in higher production costs and delivery prices $[11,16]$. Despite the growth in food delivery service expenditure and the increase in average delivery order price, the goals of the $\mathrm{O} 2 \mathrm{O}$ food business have already changed from offering cheaper and faster food to providing high quality dining experience, which includes healthier and more a diverse choice of dishes, a safer food-preparation and delivery system, and more efficient service platform in the last 3 years [15, 17]. More discussion on the percentage of increase in average spend across consumer type should be discussed in future studies on $\mathrm{O} 2 \mathrm{O}$ food industry in China.

With the epidemic of COVID-19 happening around the world, the Chinese $\mathrm{O} 2 \mathrm{O}$ food delivery business has been playing an important role in dietary behavioral change among Chinese people. A study on dietary diversity among Chinese residents during the COVID-19 has shown that more than half of the residents $(55.9 \%)$ have tried the $\mathrm{O} 2 \mathrm{O}$ online food delivery service during the pandemic [18]. According to the O2O food company "Eleme's data platform, from February 2020 to March 2020, headed by first-tier cities such as Beijing and Shanghai, many high-end brand restaurants such as Michelin restaurant, the Star Hotel Group launched its own delivery business across the country, which has got special attention by the consumer market [19]. The elevated food delivery service provided by the $\mathrm{O} 2 \mathrm{O}$ food platforms has become an ideal choice of dining for people who pursue highquality and safe food at home during the epidemic.

\section{Diversification of the $\mathbf{0 2 0}$ food choice}

The $\mathrm{O} 2 \mathrm{O}$ delivery industry entered a period where it aimed for greater product diversity and quality. Food delivery was no longer limited to simple meals and fast food [20]. Compared to 2017, more customers in 2019 ordered for lunch and dinner and hot pot delivery service was growing rapidly [21]. The increasing availability and popularity of items such as hotpot and traditional Cantonese food, which were once unsuitable for delivery, reflected a demand for diversification in delivery food [22]. In addition, the delivery service itself had expanded to include fresh grocery, everyday items and health products, etc., in order to satisfy customers' everyday needs [23]. Table 1 shows a general list of goods provided by the main $\mathrm{O} 2 \mathrm{O}$ food platforms in China. Lastly, the $\mathrm{O} 2 \mathrm{O}$ delivery industry witnessed the emergence of new jobs. Besides delivery bikers, novel positions like delivery station managers, delivery dish coordinators, delivery operating planners, and online restaurant decorators generated new employment opportunities [4]. At present, the $\mathrm{O} 2 \mathrm{O}$ market is strongly penetrated in first-tier and second-tier cities, with the proportion of second-tier, third-tier, and lower-tier cities rising, among which the proportion of third-tier and lower-tier cities has reached $44.2 \%$ [4]. There were more than 10 billion $\mathrm{O} 2 \mathrm{O}$ delivery men in 2018 [24]. In the first three months of 2019, Eleme, the largest $\mathrm{O} 2 \mathrm{O}$ platform in China owned by Alibaba, recruited more than 6000 employees covering jobs in merchant service, product research and development, distribution management and other aspects [25]. With the expansion of the $\mathrm{O} 2 \mathrm{O}$ market, new jobs with different education level requirements offered by this industry emerged around the nation [25].

It is worth noticing that Kentucky Fried Chicken, McDonald's, and Dicos were among the top 10 delivery food brands. Fast food, desserts, and drinks accounted for a majority of delivery food consumption in 2019 [4]. Fast food and snacks constituted $69.0 \%$ of the food category, while milk tea and juice made up $67.7 \%$ of the desserts and drinks category [4]. The majority of the delivery food customers preferred food items that were salty and spicy [4]. Some studies have pointed to the connection between fast food consumption and obesity [8, 26-30]. Evidence has shown that some characteristics of fast food, including excessive portion size, palatability that emphasizes taste preferences for sugar, salt, and fat, and high energy density and high glycemic load, could promote a positive energy balance and thereby result in weight gain and insulin resistance, further increase the risk of obesity and type 2 diabetes [1, 31].

\section{The concern and solution on food safety}

While $\mathrm{O} 2 \mathrm{O}$ food delivery industry is increasingly capable of catering to its customers' needs with a convenient and diverse 
selection of food, concern with regards to food safety emerging from studies in China $[32,33]$. The $\mathrm{O} 2 \mathrm{O}$ food delivery platforms were considered as a new mode of foodborne disease transmission [32]. Food handling practices were also viewed as a potential risk of acute gastroenteritis outbreaks due to the lack of surveillance and supervision [33]. The Chinese government has been trying to address the food safety issue in $\mathrm{O} 2 \mathrm{O}$ food business. China's regulation named "Measures for the Supervision and Administration of Food Safety in Online Catering Services" took effect on January 1, 2018, which requires O2O food businesses to follow regulations such as acquiring business license and publishing their name, address and quantitative classification information online [34, 35]. China has also published a series of regulations concerning the delivery process in recent years requiring all food delivery businesses to have their delivery packages sealed to prevent contamination during delivery $[36,37]$. The $\mathrm{O} 2 \mathrm{O}$ food platforms also established regulations to assess different types of non-reusable delivery food containers to ensure their quality and sustainability [38]. In 2018, a prominent Chinese O2O food delivery platform took the lead in promoting new storage equipment, developing a cleaning and disinfection procedure for delivery boxes, and incorporating kitchen live streaming to help ensure delivery food safety [39]. In addition, several major O2O food delivery platforms started to provide food safety insurance, with which customers ordering products with "qualified" labels from the platforms are entitled to a compensation if they experience food safety issues [40]. Going forward, food delivery platforms should encourage businesses to disclose information regarding food safety, such as quantitative classification information, so that customers can make informed decisions and food safety hazards can be avoided [41-45].

\section{Conclusion}

As shown in Table 2, the $\mathrm{O} 2 \mathrm{O}$ delivery industry in China has developed and changed in many directions since 2017. Having achieved the initial expansion, the $\mathrm{O} 2 \mathrm{O}$ industry has shifted its priority from quantity to quality and diversity. In the process, $\mathrm{O} 2 \mathrm{O}$ delivery industry both accommodated and reshaped its customers. On top of that, important regulations were put in place to standardize and regulate $\mathrm{O} 2 \mathrm{O}$ business practices both online and offline. China's O2O delivery industry warrants further attention and studies as it grows and develops in the future. Future studies should focus on its economic, behavioral, and health impacts on the population level as it encompasses both great risks and rewards.

Sources of support: This work was supported by the grant from the Cyrus Tang Foundation (419600-11102), with 
additional grants from the China Medical Board (CMB) Collaborating Program (15-216 and 12-108).

\section{Compliance with ethical standards}

Conflict of interest We declare that we have no personal or financial relationships with other individuals or organizations that can improperly affect our work. There is no interest of any nature in any product, service, and/or company that could be considered as affecting the position and views presented in this study.

Publisher's note Springer Nature remains neutral with regard to jurisdictional claims in published maps and institutional affiliations.

\section{References}

1. Maimaiti M, Zhao X, Jia M, Ru Y, Zhu S. How we eat determines what we become: opportunities and challenges brought by food delivery industry in a changing world in China. Eur J Clin Nutr. 2018;72:1282-6.

2. China Internet Network Information Center (CNNIC), 2018. 41th Statistical report on the development of China Internet network. Available from: http://www.cac.gov.cn/2018-01/31/c_1122347026. htm.

3. China Internet Network Information Center (CNNIC), 2019. 44th Statistical report on the development of China Internet network. Available from: http://www.cac.gov.cn/2019-08/30/c 1124938750.htm

4. Useit, 2019. Research report on China's takeaway industry in the first half of 2019. Available from: https://www.useit.com.cn/threa d-24845-1-1.html.

5. China Report Network(CRN), 2019. Analysis of the development status and prospects of China's catering takeaway industry in 2019. Available from: http://free.chinabaogao.com/shipin/201901/ 01263960362019.html.

6. Blue Cat Data, 2019. 2019 China takeaway industry analysis report. Available from: https://weibo.com/ttarticle/p/show?id= 2309404418025360064567.

7. IiMedia Research Group, 2019. 2018-2019 China online take-out market research report. Available from: https://www.iimedia.cn/ c400/64223.html.

8. Jiang Y, Wang J, Wu S, Li N, Wang Y, Liu J, et al. Association between take-out food consumption and obesity among Chinese university students: a cross-sectional study. Int J Environ Res Public Health. 2019;16:1071.

9. Landstrom E, Hursti UK, Becker W, Magnusson M. Use of functional foods among Swedish consumers is related to healthconsciousness and perceived effect. Br J Nutr 2007;98:1058-69.

10. Shi YJ. The truth of the rise in takeaway prices in 2019: giants officially entered the traffic harvesting stage $[\mathrm{J}]$. Chinese and foreign management, 2019 (03): 64-67. ISSN:1002-6525.

11. Sina Finance, 2019. Unaffordable takeaway: analysts say takeaway prices have risen since 2019. Available from: http://finance. sina.com.cn/consume/puguangtai/2019-02-28/docihsxncvf8506434.shtml.

12. Lead of finance and economics, 2019. The delivery platform has raised the commission on service charges, so it looks like we're going to have to give back the "king food" we used to eat. Available from: https://baijiahao.baidu.com/s?id=1625873490474205097\&w $\mathrm{fr}=$ spider\&for $=\mathrm{pc}$.

13. CCTV's finance and economics, 2019. Some delivery platforms have raised service fees. Will consumers pay for the extra costs? Available from: https://baijiahao.baidu.com/s?id=1622971411527075226\&w $\mathrm{fr}=$ spider \&for $=\mathrm{pc}$.

14. Sohu News, 2018. Behind the rise of online delivery food, these changes are happening in the restaurant industry that are affecting your business. Available from: https://www.sohu.com/a/ 240771875 100140600.

15. Xinhua News, 2018. Shifting focus of online food delivery industry: "high quality". Available from: http://www.xinhuanet. com/info/2018-01/29/c_136932500.htm.

16. IiMedia Research Group, 2019. Interpretation of the user scale, development status and future trends of China's online food delivery industry in 2019. Available from: https://www.iimedia. $\mathrm{cn} / \mathrm{c} 1020 / 65467 . \mathrm{html}$

17. Qudong China, 2020. Meituan $\mathrm{O} 2 \mathrm{O}$ food platform attaches great importance to food safety. Available from: https://news.qudong. com/article/342681.shtml.

18. Zhao A, Li Z, Ke Y, et al. Dietary diversity among Chinese residents during the COVID-19 outbreak and its associated factors. Nutrients. 2020;12:E1699.

19. FoodDaily, 2020. High-end restaurants start "star food delivery", Epidemic emerged a new momentum of quality food delivery market? Available from: http://www.foodaily.com/market/show. php?itemid $=21713$.

20. China Industry Information Network, 2018. The current market situation and future development forecast of China's online food and beverage delivery industry in 2018. Available from: http://www.chyxx.com/industry/201808/666954.html.

21. IiMedia Research Group, 2019. 2019 Chinese food industry big data monitoring and new business model research report. Available from: https://www.iimedia.cn/c400/65246.html.

22. CBNData, 2019. Three changes in the takeaway market. Available from: https://www.cbndata.com/information/12495.

23. Useit, 2019. Trustdata: analysis report on the development of china's takeaway industry in the first half of 2019. Available from: https://www.useit.com.cn/thread-24499-1-1.html.

24. China Economic Net, 2018. New forms of consumption have driven employment and contributed tens of millions of jobs to the take-out and express delivery industries. Available from: http://app.myzaker. com/news/article.php?pk=5c8350d277ac6464ba63983b.

25. Sohu News, 2019. "Eleme" and "Koubei" will hire another 5,000 people this year, driving 1 million new jobs in the industry. Available from: https://www.sohu.com/a/297972472_120025244.

26. Virtanen M, Kivimäki H, Ervasti J, Oksanen T, Pentti J, Kouvonen $\mathrm{A}$, et al. Fast-food outlets and grocery stores near school and adolescents' eating habits and overweight in Finland. Eur J Public Health. 2015;25:650-5.

27. Anderson B, Rafferty AP, Lyon-Callo S, Fussman C, Imes G. Fast-food consumption and obesity among Michigan adults. Prev Chronic Dis. 2011;8:A71.

28. Fraser LK, Clarke GP, Cade JE, Edwards KL. Fast food and obesity: a spatial analysis in a large United Kingdom population of children aged 13-15. Am J Prev Med. 2012;42:e77-e85.

29. Ko GT, Chan JC, Tong SD, Chan AW, Wong PT, Hui SS, et al. Associations between dietary habits and risk factors for cardiovascular diseases in a Hong Kong Chinese working populationThe "Better Health for Better Hong Kong" (BHBHK) health promotion campaign. Asia Pac J Clin Nutr. 2007;16:757-65.

30. Shan XY, Xi B, Cheng H, Hou DQ, Wang Y, Mi J. Frequency and behavioral risk factors of overweight and obesity among children aged 2-18 in Beijing, China. Int $\mathrm{J}$ Pediatr Obes. 2010;5:383-9.

31. Pereira MA, Kartashov AI, Ebbeling CB, Van Horn L, Slattery ML, Jacobs DR Jr, et al. Fast-food habits, weight gain, and insulin resistance (the CARDIA study): 15-year prospective analysis. Lancet. 2005;365:36-42. 
32. Jiang M, Zhu F, Yang C, Deng Y, Kwan P, Li Y, et al. 2020. Whole-genome analysis of salmonella enterica serovar enteritidis isolates in outbreak linked to online food delivery, Shenzhen, China, 2018. Emerg Infect Dis. 2020;26:789-92.

33. Lu Y, Ma M, Wang H, Wang D, Chen C, Jing Q, et al. An outbreak of norovirus-related acute gastroenteritis associated with delivery food in Guangzhou, southern China. BMC Public Health. 2020;20:25

34. Liu P, Li WT. Online food ordering food safety supervision: based on the perspective of intelligent supervision theory [J]. J Cent China Norm Univ (Humanities Soc Sci). 2018;57:1-9.

35. China Government Website, 2017. Interpretation of the measures for the supervision and administration of food safety in online catering services. Available from: http://www.gov.cn/zhengce/ 2017-11/11/content_5238927.htm.

36. China council for the promotion of international trade, 2017. food delivery service specification. Available from: http://www.ccpit.org/ Contents/Channel_4113/2017/0807/855259/content_855259.htm.

37. Sina Technology, 2019. Put 70 million food safety seals across the country. Available from: http://news.winshang.com/html/065/ 4339.html.

38. Sohu Net, 2018. Promote the use of hot and cold incubators to strictly control food safety risks. Available from: http://www. sohu.com/a/217798280_311820.
39. Cnbeta, 2018. Takeaway establishes. "Ming Chu Liang Zhao" alliance. Available from: https://www.cnbeta.com/articles/tech/ 747145.htm.

40. Tengcent News, 2018. Liability insurance has been issued by the $\mathrm{O} 2 \mathrm{O}$ food platform to ensure the quality and safety of online delivery food. Available from: https://new.qq.com/omn/ 20181221/20181221A001YO.html.

41. Hong L, Yin XR, Zhang XC. Research on food safety status of online ordering platform based on negative reviews [J]. Commercial Economic Research, 2019 (09): 92-95. ISSN:2095-9397.

42. Cunningham A. Toxic leftovers. Sci N. 2006;169:389-90.

43. Varshavsky JR, Morello-Frosch R, Woodruff TJ, Zota AR. Dietary sources of cumulative phthalates exposure among the U.S. general population in NHANES 2005-2014. Environ Int. 2018. https://doi.org/10.1016/j.envint. e-pub ahead of print February 29.

44. Garciaarias MT, Alvarez PE, Garcialinares MC, Garciafernandez MC, Sanchezmuniz FJ. Cooking-freezing-reheating (cfr) of sardine (sardinapilchardus) fillets. Effect of different cooking and reheating procedures on the proximate and fatty acid compositions. Food Chem. 2003;83:349-56.

45. Li Z, Zhao GS, Jiang ML. Problems and countermeasures of takeaway distribution based on $\mathrm{O} 2 \mathrm{O}$ Model [J]. E-commerce, 2019 (08): 1-2. ISSN:1009-6108. 